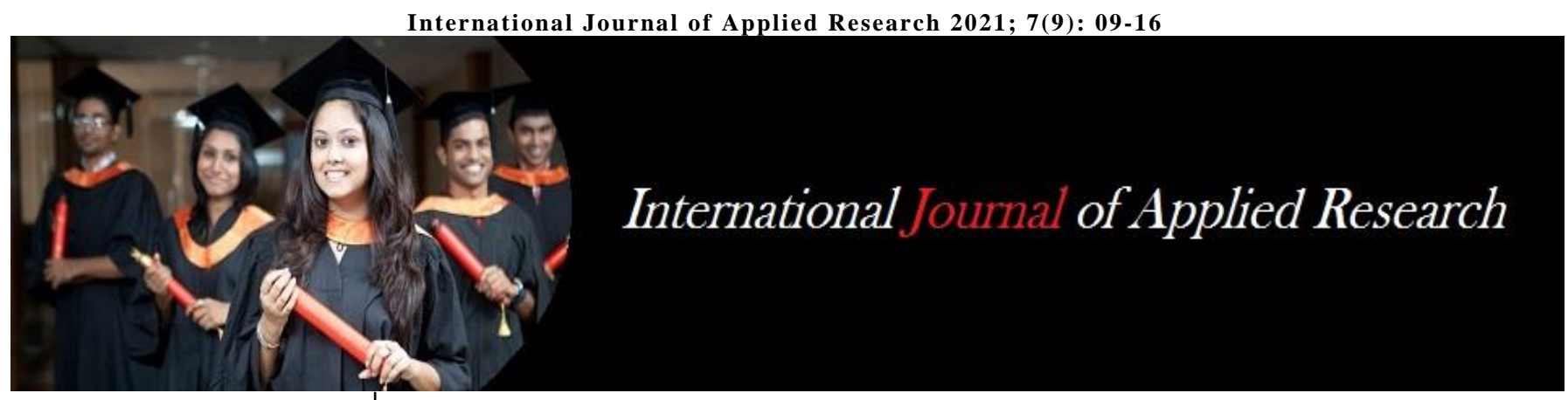

ISSN Print: 2394-7500 ISSN Online: 2394-5869 Impact Factor: 8.4 IJAR 2021; 7(9): 09-16 www.allresearchjournal.com Received: 08-07-2021 Accepted: 12-08-2021

Rais Ahmad

Tutor, Govt. College of

Nursing Srinagar, Higher

Education Department

Jammu \& Kashmir, India

Dr. Mehmooda Regu Professor cum Principal,

Madre-Maherban Institute Of

Nursing Sciences and

Research, SKIMS, Soura,

Srinagar, Jammu \& Kashmir,

India

Bilques Yasmeen

Tutor, Madre-Maherban Institute Nursing Science and Research SKIMS, Soura, Srinager, Jammu \& Kashmir, India
Corresponding Author: Rais Ahmad

Tutor, Govt. College of Nursing Srinagar, Higher Education Department Jammu \& Kashmir, India

\section{Quasi-experimental study to assess the impact of Self Instructional module (SIM) on knowledge regarding management of swine Flu (H1N1 Influenza) among general nursing midwifery (GNM) students of ancillary medical training school, Shireen Bagh, Srinagar, Kashmir}

\author{
Rais Ahmad, Dr. Mehmooda Regu and Bilques Yasmeen
}

DOI: https://doi.org/10.22271/allresearch.2021.v7.i9a.8908

\begin{abstract}
Swine flu (H1N1 influenza) is a respiratory disease caused by viruses (influenza viruses) that infect the respiratory tract of pigs and result in nasal secretions, a barking-like cough, decreased appetite, and listless behavior. It is caused due to new influenza virus called H1N1 virus. Swine flu virus targets the body's respiratory cells and damages the lining of the respiratory tract, leading to swelling and inflammation of the tract. Identification of disease is based on clinical symptoms and confirmation is done by various laboratory tests using PCR based kits. Treatment mainly involves use of different Antiviral drugs along with involvement of Indian system of medicine to some extent. The best treatment for swine influenza infection in humans is prevention by vaccination. Although vaccination is the best way to prevent the swine flu, if, in the future, vaccine supplies do not meet demands, there are some things people can do to prevent infection. Without vaccination, the best strategy is to not allow any virus type to contact a person's mucus. Infected people can wear surgical masks to reduce the amount of droplet spray from coughs and sneezes and throw away contaminated tissues (WHO 2009). Also we can kill or inactivate the virus before it reaches a human cell by using soap and water to clean our hands; washing clothing and taking a shower will do the same for the rest of our body. Use an alcohol-based hand sanitizer if soap and water are not readily available, Globally, India was one among the most affected countries for cases and deaths of swine flu (H1N1 influenza) during 2009 influenza pandemic with lot of public hype and panic. Keeping these things in view a quantitative, quasiexperimental two group pretest posttest research design study was conducted to assess the knowledge regarding management of Swine Flu (H1N1 Influenza) for which 60 subjects were selected by simple random sampling. After data collection structured knowledge questionnaire was used to assess the knowledge among both the groups (control and experimental group). The data was analyzed by descriptive and inferential statistics using chi-square and t-test. The findings revealed that majority of the study subjects $27(90 \%)$ had excellent knowledge, 3(10\%) had good knowledge and none of the subjects had neither average nor below average knowledge with posttest mean score 43.37, median 44 and standard deviation 2.17 in experimental group. Study concludes that there was gain in knowledge among students after importing self-instructional module. The study also concluded that there was statistically no association was found between age, Residence, Family Income and source of information of students with their pre-test knowledge scores $(p>0.05)$.
\end{abstract}

Keywords: impact, self instructional module, knowledge, skill, demonstration, swine flu (H1N1), GNM students

\section{Introduction}

Swine flu (H1N1 influenza or swine influenza) is a respiratory infectious disease caused by type A influenza virus that regularly causes outbreaks of influenza in pigs. It is also called as pig flu or hog flu. The classical swine flu virus (influenza type A H1N1 virus) was first isolated from a pig in $1930^{[1]}$. 
As of June 2009, the CDC (Centers for Disease Control and Prevention) has identified that Influenza viruses from different species infects pigs, thus the viruses can reassort (i.e. swap genes) and new viruses that are a mix of swine, human and/or avian influenza viruses can emerge. At this time, there are four main subtypes of influenza type A virus that have been isolated in pigs: H1N1, H1N2, H3N2, and $\mathrm{H} 3 \mathrm{~N} 1$. Most recently isolated influenza viruses from pigs, however, have been $\mathrm{H} 1 \mathrm{~N} 1$ viruses ${ }^{[2]}$.

The HINI is one type of swine flu which is very different from other strains of swine flu. It actually develops from a combination of avian (bird), swine (pig) and human flu virus and is more contagious than other typical forms of swine flu. The cause of the 2009 swine flu was influenza- type A virus, designated as $\mathrm{H} 1 \mathrm{~N} 1$. It has this designation or name because of the two major antigens $(\mathrm{H}$ and $\mathrm{N})$ detectable on its surface by immunological techniques $(\mathrm{H}$ or hemagglutinin and $\mathrm{N}$ or neuraminidase). The eight RNA strands from novel H1N1 flu have one strand derived from human flu strains, two from avian (bird) strains, and five from swine strains ${ }^{[3]}$.

H1N1 viruses do not normally infect humans. But, sporadic human infections with swine flu have occurred. Initially, these cases occur in persons with direct exposure to pigs [e.g. children near pigs at zoo's or workers in the swine industry] (World Health Organization [WHO], 2009) ${ }^{[4]}$.

Seasonal influenza occurs every year and the viruses change each year. Many people have some immunity to the circulating virus that helps to restrict the infections. Some countries also use seasonal influenza vaccines to reduce illness and deaths. But influenza A (H1N1) is a new virus and one to which most people have no or little immunity to, therefore, this virus could cause more infections than are seen with seasonal flu (WHO, 2009) ${ }^{[5]}$.

By June 2009, the WHO has identified that the new influenza A (H1N1) appears to be as contagious as seasonal influenza, and is spreading fast, particularly among young people (ages 10 to 45 years). The severity of the disease ranges from very mild symptoms to severe illnesses that can result in death. Most people who get the virus, experience the milder illness and recover without antiviral treatment or medical care. In case of serious illness, more than half of hospitalized people had underlying health conditions or weak immune systems (CDC, 2009) ${ }^{[2]}$.

Flu viruses spread mainly from person to person through coughing or sneezing by people with influenza. Sometimes people may become infected by touching something, such as a surface or object with flu viruses on it and then touching their mouth or nose.

The symptoms of swine flu are similar to most influenza infections such as fever (100 F or greater), cough (usually dry), nasal secretions, fatigue, and headache, with fatigue being reported in most infected individuals. Some patients may also get a sore throat, rash, body (muscle) aches or pains, headaches, chills, nausea, vomiting, and diarrhea. The incubation period from exposure to first symptoms is about one to four days, with an average of two days. The symptoms last about one to two weeks and can last longer if the person has a severe infection. Some patients develop severe respiratory symptoms, such as shortness of breath, and need respiratory support (such as a ventilator to breathe for the patient).Death often occurs from secondary bacterial infection of the lungs; appropriate antibiotics need to be used in these patients. The usual mortality (death) rate for typical influenza $\mathrm{A}$ is about $0.1 \%{ }^{[3]}$.
Swine flu is diagnosed clinically by the patient's history of association with people known to have the disease and their symptoms listed above. Usually, a quick test (for example, nasopharyngeal swab sample) is done to see if the patient is infected with influenza A or B virus. Most of the tests can distinguish between A and B types. The test can be negative (no flu infection) or positive for type A and B. If the test is positive for type B, the flu is not likely to be swine flu. If it is positive for type $\mathrm{A}$, the person could have a conventional flu strain or swine flu. In 2010, the FDA approved a commercially available test that could detect H1N1 within four hours. Most of these rapid tests are based on PCR (Polymerase Chain Reaction) technology. Swine flu is more accurately diagnosed by identifying the particular antigens (surface proteins) associated with the virus type. In general, this test is done in a specialized laboratory and is not done hospital laboratories. However, hospital laboratories are able to send specimens to specialized laboratories so that flu virus strains are diagnosed ${ }^{[4]}$.

The best treatment for influenza infections in humans is prevention by vaccination. The first $\mathrm{H} 1 \mathrm{~N} 1$ vaccine released in early October 2009 was a nasal spray vaccine that was approved for use in healthy individuals with the age group of 2-49. The injectable vaccine, made from killed H1N1, became available in the second week of Oct. 2009. This vaccine was approved for use in ages 6 months to the elderly, including pregnant females. Both of these vaccines were approved by the Centers for Disease Control and Prevention (CDC) only after they had conducted clinical trials to prove that the vaccines were safe and effective. A new influenza vaccine preparation is the intradermal (trivalent) vaccine is available; it works like the shot except the administration is less painful. It is approved for ages 1864 years.

Two antiviral agents have been reported to help prevent or reduce the effects of swine flu. They are Zanamivir (Relenza) and Oseltamivir (Tamiflu), both of which are also used to prevent or reduce influenza A and B symptoms. These drugs should not be used indiscriminately, because viral resistance to them. Severe infections in some patients may require additional supportive measures such as ventilation support and treatment of other infections like pneumonia that can occur in patients with a severe flu infection. The CDC has suggested in their guidelines that pregnant females can be treated with the two antiviral agents [5].

Although vaccination is the best way to prevent the swine flu, if, in the future, vaccine supplies do not meet demands, there are some things people can do to prevent infection. Without vaccination, the best strategy is to not allow any virus type to contact a person's mucus. Infected people can wear surgical masks to reduce the amount of droplet spray from coughs and sneezes and throw away contaminated tissues (WHO, 2009) ${ }^{[6]}$.

Yet there are still some other methods available to prevent flu virus infection are a combination of methods that are aimed at fulfilling the very basic principle that if the virus doesn't reach an individual's mucus membrane cells, infection will be prevented.

The methods are as follows:

1. Kill or inactivate the virus before it reaches a human cell by using soap and water to clean your hands; washing clothing and taking a shower will do the same for the rest of your body.

2. Use an alcohol-based hand sanitizer if soap and water are not readily available, and use sanitizers on objects 
that many people may touch (for example, doorknobs, computer keyboards, handrails, phones).

3. Do not touch your mouth, eyes, nose, unless you first do steps 1 or 2 above.

4. Avoid crowds, parties, and especially people who are coughing and sneezing (most virus- containing droplets do not travel more than 4 feet, so experts suggest 6 feet away is a good distance to stay)

5. Avoid touching anything within about 6 feet of an uncovered cough/sneeze, because the droplets that contain virus fall and land on anything usually within that range.

6. Studies show that individuals who wear surgical or N95 particle masks may prevent inhalation of some H1N1 virus, but the masks may prevent only about $50 \%$ of airborne exposures and offer no protection against surface droplets. However, masks on H1N1 infected people can markedly reduce the spread of infected droplets.

These six steps can help prevent individuals from getting H1N1 infection (WHO, 2009). However, there are some additional strategies that may also help prevent viral infections in unvaccinated people according to some investigators. Saline nasal washes and gargling with saline (or a commercial product) as a way to reduce or eliminate viral virus from mucus membranes has been suggested ${ }^{[7]}$.

People with suppressed immune systems historically have worse outcomes than uncompromised individuals; investigators suspect that as swine flu spreads, the mortality rates may rise and be high in this population. Current data suggest that pregnant individuals, children under 2 years of age, young adults, and individuals with any immune compromise are likely have a worse prognosis. Complications of swine flu may resemble severe viral pneumonia or the SARS (severe acute respiratory syndrome) caused by a corona virus strain. Other complications include sinus and ear infections, asthma exacerbations, and/or bronchitis ${ }^{[8]}$.

Braunwald, (2009) conducted a cross sectional study to assess the knowledge of the Australian community towards the influenza at university of New South Wales, Sydney. The sample consisted of 620 respondents. The findings reveal that about 447 were aware of pandemic H1N1, but 273 felt that they did not have enough knowledge about the situation. The study suggested emphasizing the efficacy of recommended actions such as hand hygiene ${ }^{[9]}$.

C. Thornton, (2009) conducted a comparative study on severe respiratory disease concurrent with the circulation of H1 N1 Influenza at National Institute of Health, Bethesda, United State America. The sample consisted 2155 cases of severe pneumonia and 6662 cases of throat infection. The total samples were 8817 patient, the nasopharyngeal specimens were checked, 2582 cases were positive for $\mathrm{H} 1 \mathrm{~N} 1$, they compared this cases according to age distribution, about $71 \%$ of cases of severe pneumonia involved patients between the age of 5 and 59 years. The study findings revealed that during the early phase of this influenza pandemic, there was sudden increase in the rate of severe pneumonia. If the vaccines supplies are limited, these findings suggested for rationale focusing on preventive efforts on younger population ${ }^{[10]}$.

According to the latest WHO statistics (as of July 2010), the virus has killed more than 18,000 people since it appeared in April 2209, however they state that the total mortality (including deaths unconfirmed or unreported) from H1N1 strains is "unquestionably higher".

In 2012 research showed that as many as 579,000 people have been killed by the disease, the majority of these deaths occurred in Africa and Southeast Asia. Now the WHO have estimated approximately 284,500 cases of swine flu is found worldwide ${ }^{[11]}$.

In 2015, the outbreak became widespread throughout India. On12 February 2015, Rajasthan declared an epidemic with reported cases 6,559 and 415 deaths. By 20 March 2015, according to the data released by Health Ministry of India, 31,974 cases had been reported and 1,895 persons had died due to this viral disease through the country ${ }^{[12]}$.

\section{Objectives of the study}

1. To assess the pre-test knowledge score regarding management of swine flu (H1N1 Influenza) among general nursing midwifery (GNM) students in both experimental and control group.

2. To assess the post-test knowledge score regarding management of swine flu (H1N1 Influenza) among general nursing midwifery (GNM) students in both experimental and control group.

3. To compare the pre-test and post-test knowledge score regarding management of swine flu (H1N1 Influenza) among general nursing midwifery (GNM) students between experimental and control group.

4. To find out the association between pre-test knowledge score regarding the management of swine flu (H1N1 Influenza) among general nursing midwifery (GNM) students with selected demographic variables (Age, Place of residence, Family Income per month, Source of information).

\section{Materials and Methods}

A quasi-experimental study design was conducted to assess the knowledge among general nursing midwifery (GNM) students of Ancillary Medical Training School Srinagar Kashmir. 60 subjects were selected by simple random sampling technique. Structure Knowledge questionnaire was adopted to collect the information from the participants in selected AMT School Srinagar. The tool consists of demographic variables and 50 items related to knowledge assessment among general nursing midwifery (GNM) students of Ancillary Medical Training School Srinagar Kashmir. Prior to data collection informed consent was obtained from the participants. The data was analyzed using descriptive and inferential statistics.

\section{Results}

Table 1: Distribution of respondents according to Age in experimental and control group

\begin{tabular}{|c|c|c|c|c|c|}
\hline Demographic Variable & Opts & Experimental Percentage & Control Percentage & Experimental Frequency & Control Frequency \\
\hline \multirow{5}{*}{ AGE IN YEARS } & 19 Years & 10 & 37 & 3 & 11 \\
\cline { 2 - 6 } & 20 Years & 67 & 37 & 20 & 11 \\
\cline { 2 - 7 } & 21 Years & 20 & 20 & 6 & 6 \\
\cline { 2 - 7 } & 22 Years & 3 & 7 & 1 & 2 \\
\hline
\end{tabular}




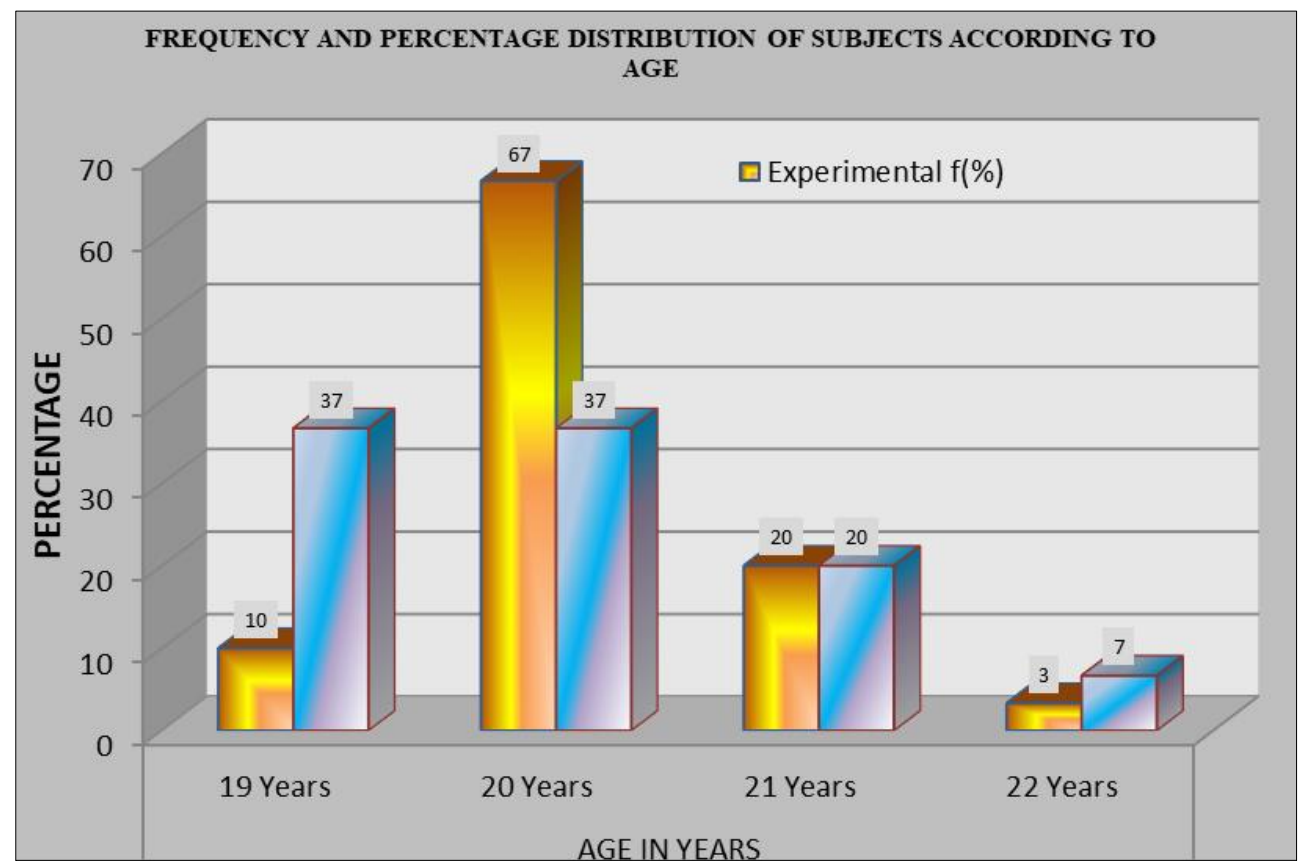

Fig 1: Bar diagram showing percentage distribution of subjects by their age in Experimental and Control Group

Table $1 \&$ Figure 1 revealed that out of 30 study subjects in an experimental group: most of the subjects $20(67 \%)$ were in the age group of 20 years, followed by $6(20 \%)$ were in the age group of 21 years, and $3(10 \%)$ in the age group of 41-60 years while minimum $1(3 \%)$ were in the age group of 22 years. While as out of 30 subjects in control group: most of the subjects $11(37 \%)$ were in the age group of 19 years \& 20 years respectively followed by $6(20 \%)$ in the age group of 21 years. while minimum $2(7 \%)$ were in the age group of 22 years and $6(12 \%)$ in the age group of 41-60 years.

Table 2: Frequency and percentage distribution of study subjects by their Place of Residence in Experimental and Control Group N= Exp30, Control-30

\begin{tabular}{|c|c|c|c|c|c|}
\hline Demographic Variable & Opts & Experimental Percentage & Control Percentage & Experimental Frequency & Control Frequency \\
\hline \multirow{2}{*}{ Place of Residence } & Rural & 73 & 70 & 22 & 21 \\
\cline { 2 - 7 } & Urban & 27 & 30 & 8 & 9 \\
\hline
\end{tabular}

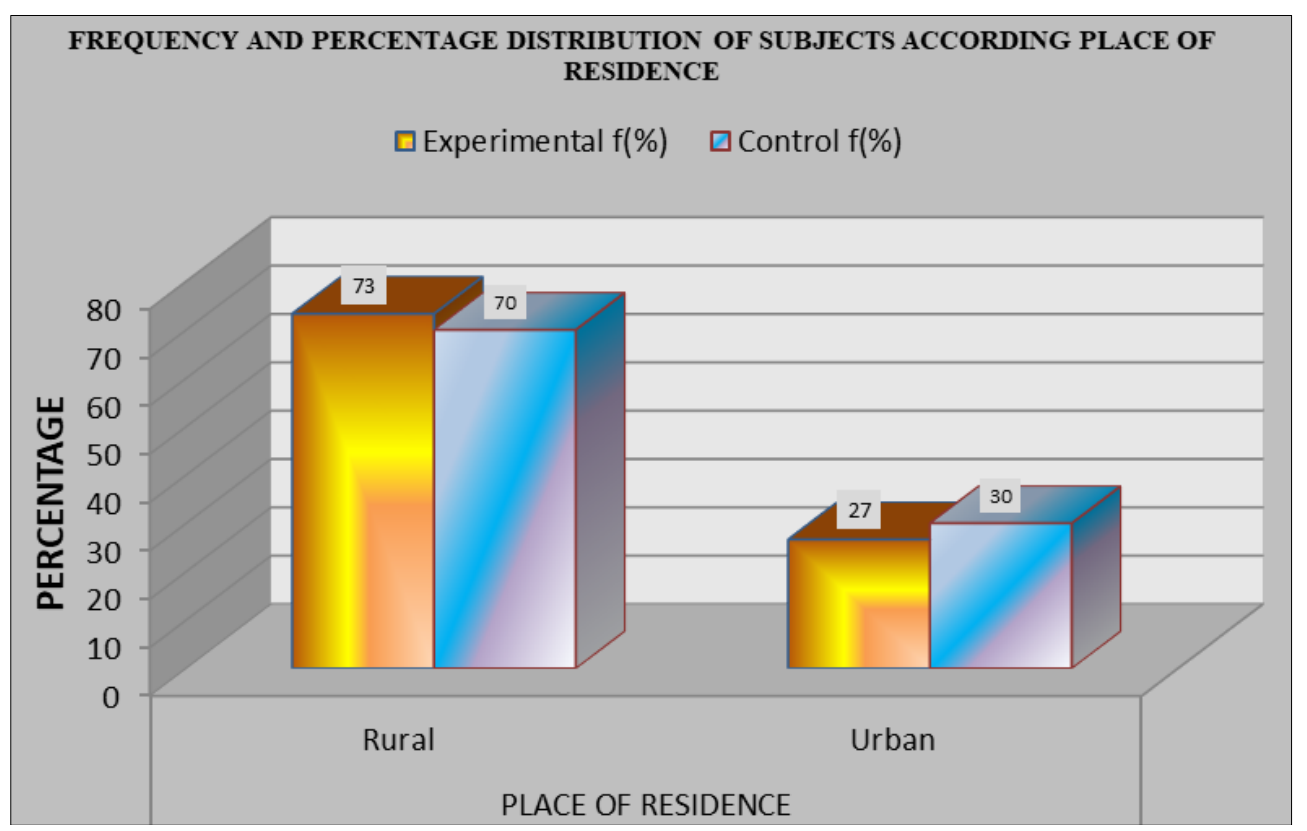

Fig 2: Bar diagram showing percentage distribution of subjects by their Place of Residence in Experimental and Control Group

Table 2 \& Figure 2 revealed that out of 30 study subjects in an experimental group: most of the subjects $22(73 \%)$ were from rural areas and $8(27 \%)$ were from urban areas. While as out of 30 study subjects in control group, most of subjects $21(70 \%)$ were from rural areas while minimum 9(30\%) were from urban areas. 
Table 3: Frequency and percentage distribution of study subjects by their family income per month in Experimental and Control Group N= Exp-30, Control-30

\begin{tabular}{|c|c|c|c|c|c|}
\hline Demographic Variable & Opts & Experimental Percentage & Control Percentage & Experimental Frequency & Control Frequency \\
\hline \multirow{4}{*}{$\begin{array}{c}\text { Family Income Per } \\
\text { Month Rs. }\end{array}$} & $5000-10000$ & 40 & 30 & 12 & 9 \\
\cline { 2 - 6 } & $10000-15000$ & 23 & 17 & 7 & 5 \\
\cline { 2 - 6 } & $15000-20000$ & 7 & 33 & 2 & 10 \\
\cline { 2 - 6 } & Above 20000 & 30 & 20 & 9 & 6 \\
\hline
\end{tabular}

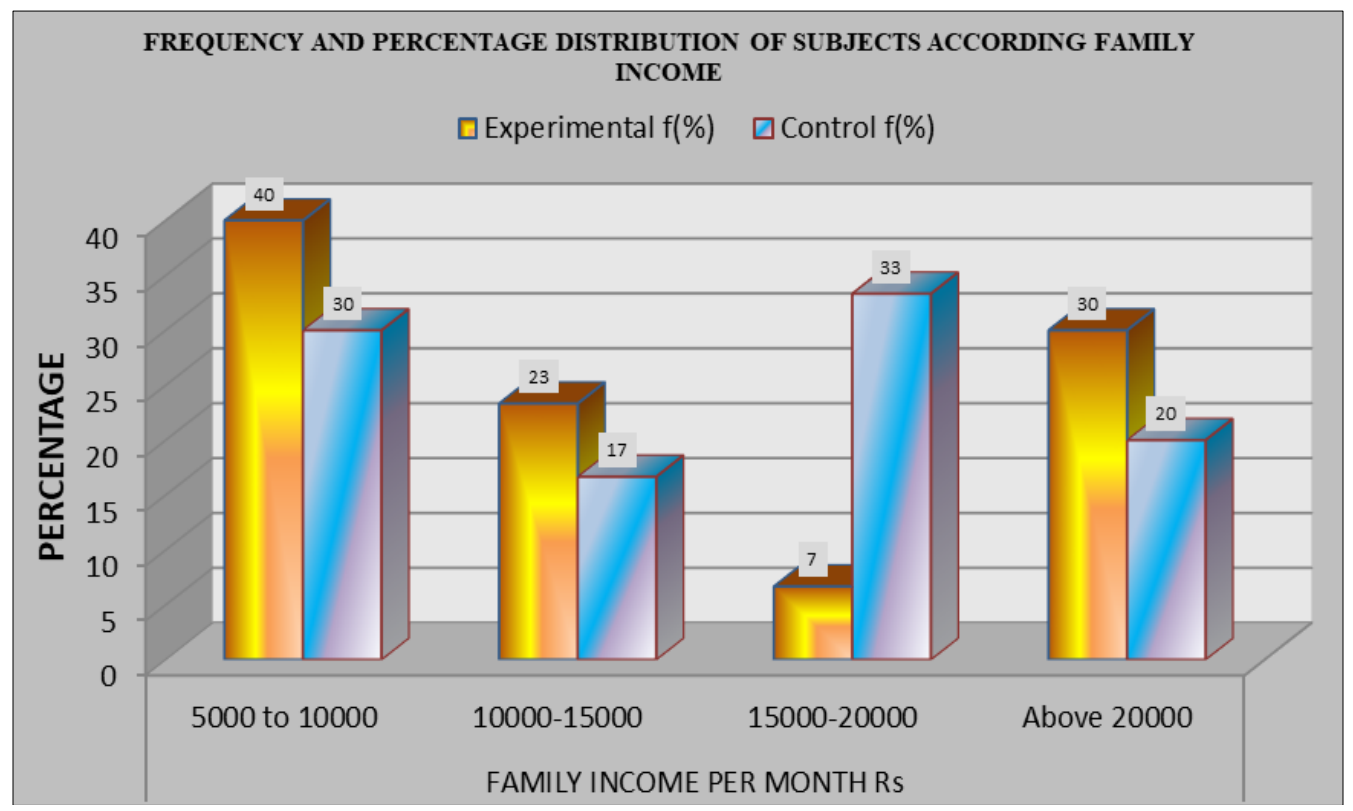

Fig 3: Bar diagram showing percentage distribution of subjects by their family income per month in Experimental and Control Group

Table 3 \& Figure 3 revealed that out of 30 study subjects in an experimental group: most of the subjects $12(40 \%)$ had between 5000-10000, followed by $9(30 \%)$ had above 20000 , $7(23 \%)$ had between 10000-15000 family income/month and $2(7 \%)$ had between 15000-20000 family income/month.
While as out of 30 study subjects in control group, most of the study subjects $10(33 \%)$ had between $15000-20000$, followed by $9(30 \%)$ had between $5000-10000,6(20 \%)$ had above 20000 and 5(17\%) had between 10000-15000 family income/month.

Table 4: Frequency and percentage distribution of study subjects source of information N= Exp-30, Control-30

\begin{tabular}{|c|c|c|c|c|c|}
\hline Demographic Variable & Opts & Experimental Percentage & Control Percentage & Experimental Frequency & Control Frequency \\
\hline \multirow{2}{*}{ Source of Information } & No & 90 & 87 & 27 & 26 \\
\cline { 2 - 6 } & Yes & 10 & 13 & 3 & 4 \\
\hline
\end{tabular}

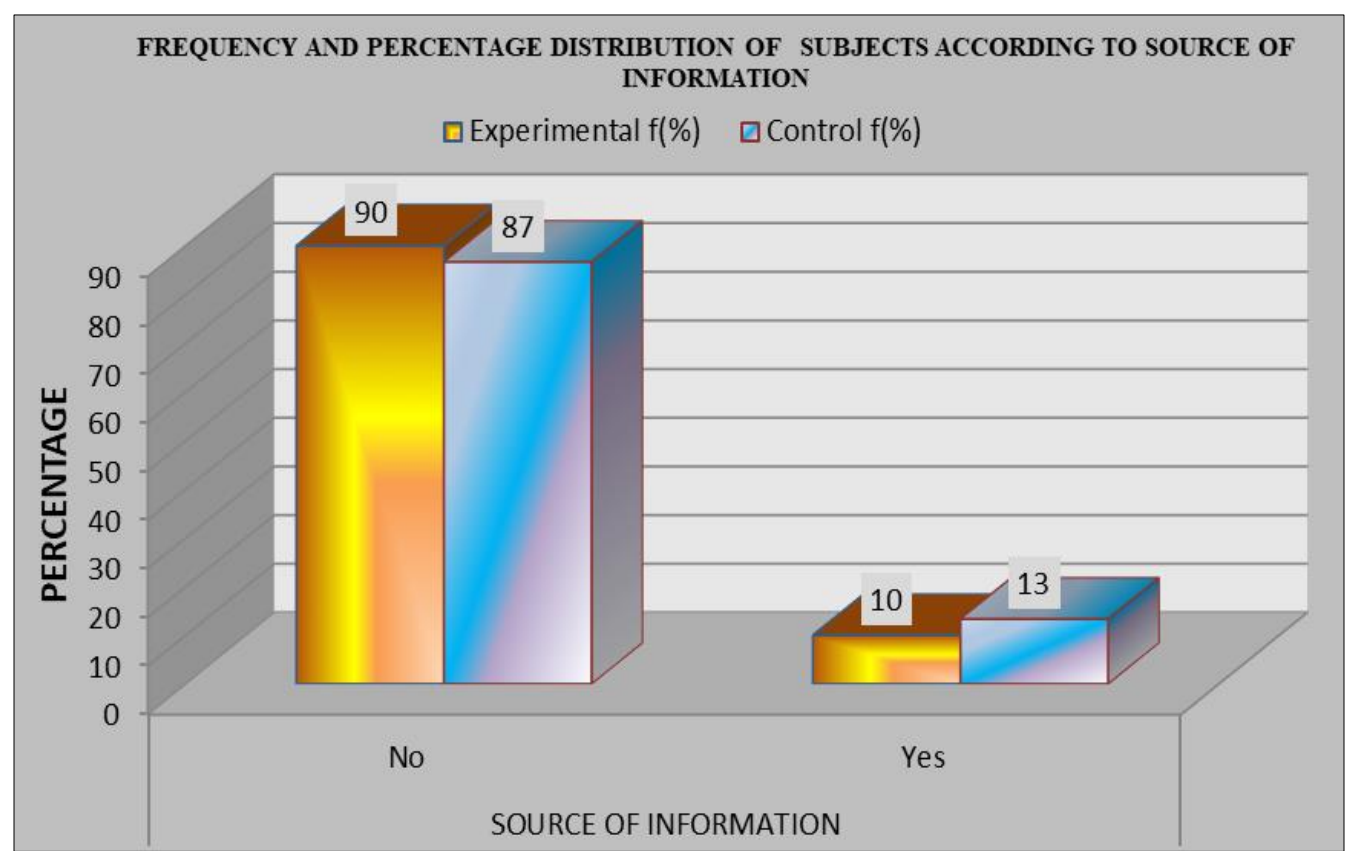

Fig 4: Bar diagram showing percentage distribution of subjects by source of information in Experimental and Control Group 
Table 4 \& Figure 4 revealed that out of 30 study subjects in an experimental group: majority of the subjects $27(90 \%)$ have not any source of information related to management of swine flu. While minimum $3(10 \%)$ have source of information related to management of swine flu $(\mathrm{H} 1 \mathrm{~N} 1$ Influenza).
While as out of 30 study subjects in control group: majority of the subjects $26(87 \%)$ have not any source of information related to management of swine flu. While minimum $4(13 \%)$ have source of information related to management of swine flu (H1N1 Influenza).

Table 5: Comparison of Pre-test and Post-test frequency \& percentage distribution of knowledge scores of study subjects regarding management of swine flu H1N1 Influenza in Experimental and Control group N= Exp-30, Control-30

\begin{tabular}{|c|c|c|c|c|}
\hline \multicolumn{7}{|c|}{ Pre-Test \& Post-Test Knowledge Score Comparison } \\
\hline Level of Knowledge Scores & Pre-test Experimental & Pre-test Control & Post-test Experimental & Post-test Control \\
\hline Below Average Knowledge(0-12) & $0(0 \%)$ & $0(0 \%)$ & $0(0 \%)$ & $0(0 \%)$ \\
\hline Average Knowledge(13-25) & $28(93.3 \%)$ & $29(96.7 \%)$ & $0(0 \%)$ & $28(93.3 \%)$ \\
\hline Good Knowledge(26-38) & $2(6.7 \%)$ & $1(3.3 \%)$ & $3(10 \%)$ & $2(6.7 \%)$ \\
\hline Excellent (39-50) & $0(0 \%)$ & $0(0 \%)$ & $27(90 \%)$ & $0(0 \%)$ \\
\hline
\end{tabular}

Maximum $=50$ Minimum $=0$

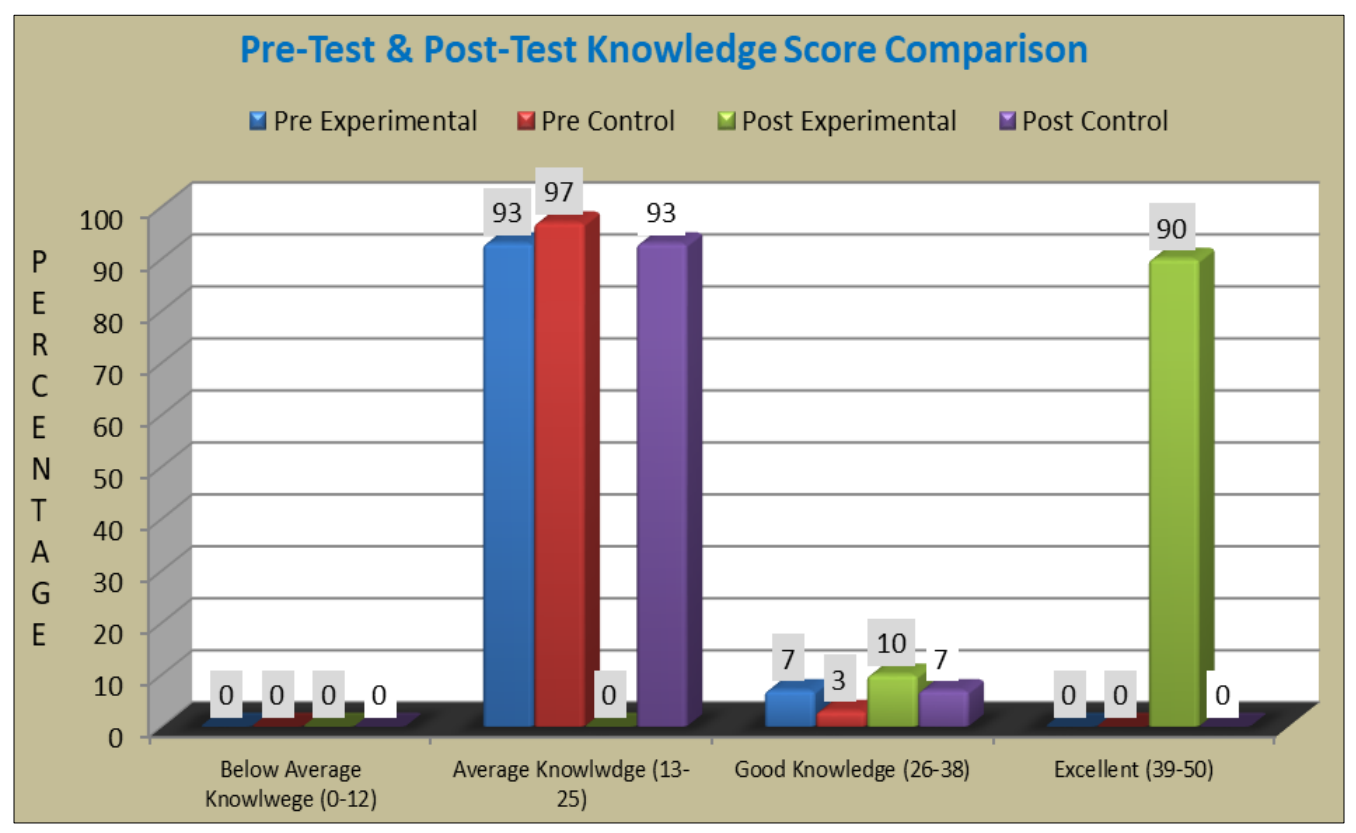

Fig 5: Bar diagram showing Comparison of Pre and Post-test percentage distribution of knowledge scores of study subjects in Experimental and Control Group

Table 5 and Figure 5 shows that in the Pre-test of an Experimental group, most of the study subjects 28(93\%) had average level of knowledge regarding management of swine flu (H1N1 Influenza), 2(7\%) of subjects have good level of knowledge, $0(0 \%)$ of study subjects had below average level of knowledge and none of $(0 \%)$ of study subjects had excellent level of knowledge regarding management of swine flu (H1N1 Influenza). While as in the Post-test of an experimental group, most of the study subjects $27(90 \%)$ had excellent level of knowledge regarding management of swine flu (H1N1 Influenza), 3(10\%) of subjects have good level of knowledge, $0(0 \%)$ of study subjects had average level of knowledge and none of $(0 \%)$ of study subjects had below average level of knowledge regarding management of swine flu (H1N1 Influenza).
While as in the Pre-test of control group, most of the study subjects 29(97\%) had Average level of knowledge regarding management of swine flu (H1N1 Influenza), 1(3\%) of subjects have good level of knowledge, $0(0 \%)$ of study subjects had below average level of knowledge and none of $(0 \%)$ of study subjects had Excellent level of knowledge regarding management of swine flu (H1N1 Influenza).

While as in the Post-test of control group most of the study subjects $28(93 \%)$ had average level of knowledge regarding management of swine flu (H1N1 Influenza), 2 (7\%) of subjects have good level of knowledge, $0(0 \%)$ of study subjects had below average level of knowledge and none of $(0 \%)$ of study subjects had excellent level of knowledge regarding management of swine flu (H1N1 Influenza).

Table 6: Comparison of Pre-test and Post-test Mean and SD of knowledge scores of study subjects regarding swine flu H1N1 Influenza in Experimental and Control group N= Exp-30, Control-30

\begin{tabular}{|c|c|c|c|c|c|c|c|c|}
\hline \multirow[b]{3}{*}{ Group } & \multirow[b]{3}{*}{$\mathrm{N}$} & \multicolumn{4}{|c|}{ Comparison of pre-test \& post-test knowledge scores } & \multirow{2}{*}{\multicolumn{3}{|c|}{ Paired T Test }} \\
\hline & & \multicolumn{2}{|c|}{ Pre test } & \multicolumn{2}{|c|}{ Post test } & & & \\
\hline & & Mean & SD & Mean & SD & df & $\mathrm{T}$ & Result \\
\hline Experimental Group & 30 & 21.93 & 1.929 & 43.37 & 2.173 & 29 & 39.561 & Significant \\
\hline Control Group & 30 & 22.267 & 1.837 & 22.37 & 1.938 & 29 & 1.361 & Non Significant \\
\hline
\end{tabular}

Maximum $=50$, Minimum $=0$ 


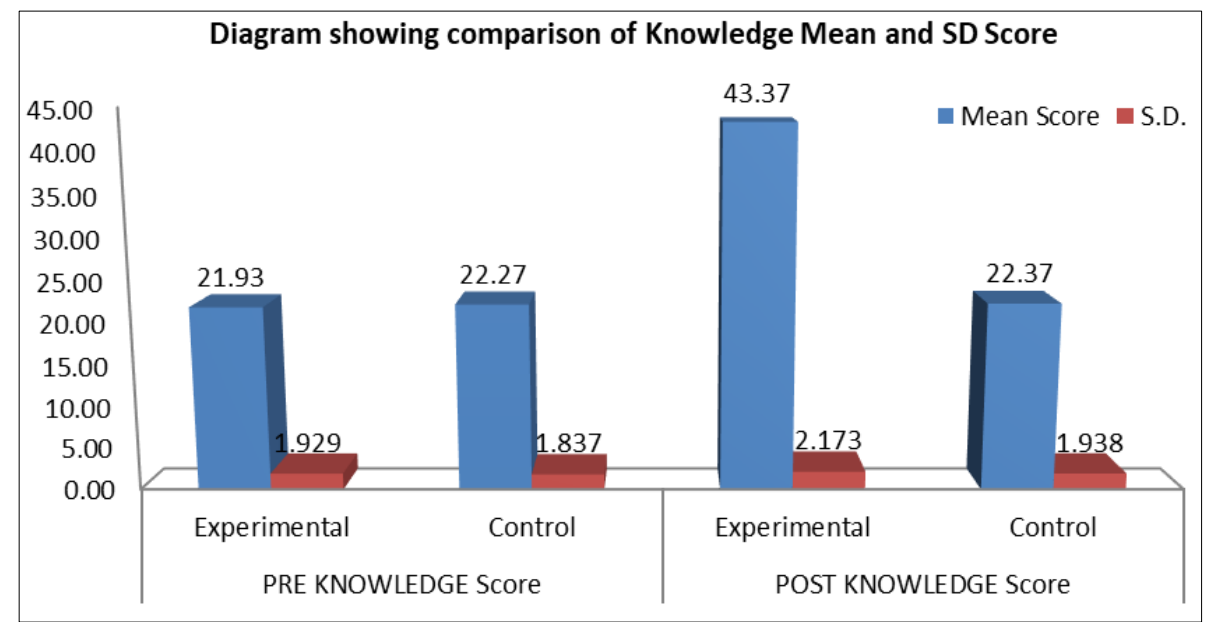

Fig 6: Bar diagram showing comparison of Pre and Post-test Mean and SD level of knowledge scores of study subjects in Experimental and Control Group

Table 6 and Figure 6 revealed that in an experimental group, the Pre-test mean knowledge score of study subjects was 21.93 and SD 1.929 and the Post-test mean knowledge score of study subjects was 43.37, SD 2.173
While as in control group, the Pre-test mean knowledge score of study subjects was 22.27, and S.D 1.837.while as the Post-test mean knowledge score of study subjects was 22.37 and SD 1.938 .

Table 7: Association of pre-test knowledge score of study subjects with their demographic variables in an experimental group: N= Exp.-30

\begin{tabular}{|c|c|c|c|c|c|c|c|c|c|c|}
\hline \multicolumn{2}{|c|}{ Demographic variables } & \multicolumn{9}{|c|}{ Association of pre-test knowledge score with demographic variables( experimental group) } \\
\hline Variables & Opts & Excellent & $\begin{array}{c}\text { Good } \\
\text { knowledge }\end{array}$ & $\begin{array}{c}\text { Average } \\
\text { knowledge }\end{array}$ & $\begin{array}{c}\text { Below average } \\
\text { knowledge }\end{array}$ & Chi test & P value & Df & $\begin{array}{l}\text { Table } \\
\text { value }\end{array}$ & Result \\
\hline \multirow{4}{*}{ Age in years } & 19 years & & 0 & 3 & & \multirow{4}{*}{1.071} & \multirow{4}{*}{0.784} & \multirow{4}{*}{3} & \multirow{4}{*}{7.815} & \multirow{4}{*}{ Ns* } \\
\hline & 20 years & & 2 & 18 & & & & & & \\
\hline & 21 years & & 0 & 6 & & & & & & \\
\hline & 22 years & & 0 & 1 & & & & & & \\
\hline \multirow{2}{*}{ Place of residence } & Rural & & 1 & 21 & & \multirow{2}{*}{0.597} & \multirow{2}{*}{0.440} & \multirow{2}{*}{1} & \multirow{2}{*}{3.841} & \multirow{2}{*}{ Ns* } \\
\hline & Urban & & 1 & 7 & & & & & & \\
\hline \multirow{4}{*}{$\begin{array}{l}\text { Family income per } \\
\text { month }\end{array}$} & $5000-10000$ & & 1 & 11 & & \multirow{4}{*}{0.982} & \multirow{4}{*}{0.806} & \multirow{4}{*}{3} & \multirow{4}{*}{7.815} & \multirow{4}{*}{ Ns* } \\
\hline & $10000-15000$ & & 0 & 7 & & & & & & \\
\hline & $15000-20000$ & & 0 & 2 & & & & & & \\
\hline & Above 20000 & & 1 & 8 & & & & & & \\
\hline \multirow{2}{*}{$\begin{array}{c}\text { Source of } \\
\text { information }\end{array}$} & No & & 2 & 25 & & \multirow{2}{*}{0.238} & \multirow{2}{*}{0.626} & \multirow{2}{*}{1} & \multirow{2}{*}{3.841} & \multirow{2}{*}{ Ns* } \\
\hline & Yes & & 0 & 3 & & & & & & \\
\hline
\end{tabular}

NS* = Not Significant

Table 7: Shows no significant association was found between Age, Residence, Family Income and Source of Information of General Nursing Midwifery (GNM) Students with their pre-test knowledge scores $(p>0.05)$. Hence null hypothesis is accepted.

\section{Conclusions}

The following conclusions were drawn on the basis of the findings of the study.

- Pretest findings showed the Knowledge score of General Nursing Midwifery (GNM) Students of Ancillary Medical Training School, Srinagar was found poor regarding management of Swine Flu (H1N1 Influenza) in both experimental and control group.

- There was improvement in knowledge score of study subjects after the implementation of Self Instructional Module (SIM) regarding management of Swine Flu (H1N1 Influenza) in experimental group as compared to control group which lacks Self Instructional Module (SIM).

- The Self Instructional Module (SIM) was found effective in improving the knowledge regarding management of Swine Flu (H1N1 Influenza) as it was evident from posttest knowledge scores and when compared with control group which lacks SIM.

- There was found no association between pre-test knowledge scores $(p>0.05)$ with selected demographic variables i.e. age, residence, family income and source of information. This indicates that an effective module of self-instructional module regarding swine flu (H1N1 Influenza) must be imparted on regular basis to preclinical General Nursing Midwifery (GNM) Students of Ancillary Medical Training School, in order to increase the knowledge regarding swine flu (H1N1 Influenza) because they are more prone for getting infected with swine flu (H1N1 Influenza) as they are in close contact with the patients and thereby so as to prevent the disease and reduce morbidity and mortality.

\section{Recommendations}

The Following studies can be undertaken in relation to present study

- A similar study need to be undertaken with a large number of samples for better generalization.

- A similar study can be conducted by seeking different teaching strategies such as structured teaching 
programme, video assisted teaching programme and video demonstration.

- A similar study can be conducted on the staff-nurses to assess the knowledge regarding Swine Flu (H1N1 Influenza).

- A True Experimental research approach can be used.

- The study can be conducted among non-nursing personnel to assess their knowledge regarding practice to prevent from Swine Flu (H1N1 Influenza) infection.

- Setting can be changed by involving more hospitals and nursing homes.

- A comparative study can be conducted to assess the knowledge and attitude regarding Swine Flu (H1N1 Influenza) among nurses in hospitals.

- A comparative study can be conducted between rural setting and urban setting related complications of Swine Flu (H1N1 Influenza).

\section{Acknowledgement}

With profound gratitude I am deeply indebted to my esteemed teacher and Guide Prof. (Dr.) Mehmooda Regu Professor cum Principal in Madre Meharban Institute of Nursing Sciences and Research SKIMS Soura, who helped me in stimulating and providing valuable suggestions, sharing knowledge and experience and encourages and helped me in all the times of research period. I am also grateful to my Co-Guide Mrs. Bilques Yasmeen who helped and guided during my research work. In addition of this finally I am deeply and heartedly grateful to all my family members who morally supported through the construction of view successfully.

\section{References}

1. Centres for Diseases Control and Prevention. Questions and Answers about H1N1 Flu (H1N1 Influenza) 2009. Retrieved from http://www.cdc.gov/H1N1 Flu//qa.htm.

2. Centres for Diseases Control and Prevention. Questions and Answers about H1N1 Flu (H1N1 Influenza) 2009. Retrieved from http://www.cdc.gov/ H1N1 Flu//qa.htm.

3. World Health Organization. Pandemic (H1N1) 2009 Retrieved from http://www.who.int/csr/disease/swineflu/en/index.html.

4. Centre for disease research and policy. Novel H1N1 Influenza (Swine Flu) 2009. Retrieved from http://www.cidrap.umn.edu/cidrap/content/influenzaofs wineflu/biofacts/swinefluoverview.html.

5. Centres for Diseases Control and Prevention. Pandemic Influenza (H1N1 Influenza) treatment 2009. Retrieved from http://www.cdc.gov/flu/swineflu/treatment facts.html.

6. World Health Organization Report pandemic (H1N1) Influenza virus vaccination 2009. Retrieved from www.who.int./csr/don/2010_02_12/en/index.html.

7. World Health Organization Report Prevention (H1N1) Influenza Virus Incidence 2009. World Wide www.WHO.int/csr/don/2010_02_12/cn/index.html.

8. H1N1 influenza Pandemic: published by WHO health topics communicable diseases, influenza news Aug 2010. Available from http://www.euro.who.int/en/whatwe-du/health-topics/communicable diseases/influenza/ news/2010/08/ who-director-general-declearesH1N1pendemic-over.

9. Braunwald. Cross-sectional study to assess the knowledge of the Austrilian Community towards the
Influenza at University of New South Wales, Sydney. JAMA- Journal of the Americian Medical Association 2009, 176.

10. Thornton C. Comparative study on severe respiratory disease concurrent with the circulation of H1N1 Influenza at National Institute of Health, Bethesda, USA. JAMA-Journal of the Americian Medical Association 2009, 150-151.

11. Indi's swine flu. Death reaches 981.2009 [cited 2009 Nov 16]; Available from URL:http:blog.taragan.com/health/2009/11/26/India'sflu-deaths-reaches 981-1763.

12. Indian swine flu. Outbreak [cited 2015, Feb 12]; 2015. Available from URL:http://en.m.wikipedia.org/w/index.html. 